NUÑEZ LEIVA, José Ignacio. "Un análisis abstracto del Derecho Penal del Enemigo a partir del Constitucionalismo Garantista y Dignatario."

Polit. crim. Vol. 4, No 8 (Diciembre 2009), Art. 3, pp. 383-407 (1-25).

[http://www.politicacriminal.cl/Vol_04/n_08/Vol4N8A3.pdf]

\title{
Un análisis abstracto del Derecho Penal del Enemigo a partir del Constitucionalismo Garantista y Dignatario. ${ }^{1}$
}

\author{
José Ignacio Núñez Leiva. \\ Abogado Pontificia Universidad Católica de Chile. \\ Profesor Universidades San Sebastián, Andrés Bello y Alberto Hurtado. \\ jinunez@uc.cl
}

\section{Resumen}

El presente artículo describe, sin considerar casos particulares - y consultando preferentemente la obra de Günther Jakobs y algunos de sus comentaristas - las principales características del denominado Derecho Penal del Enemigo en abstracto. Ello con el propósito de evaluar su compatibilidad con el concepto de Dignidad Humana, presente en la mayoría de los ordenamientos constitucionales contemporáneos y en el sistema de protección de los Derechos Humanos. Se razona, aplicando el marco general propuesto por el neoconstitucionalismo teórico y el garantismo, especialmente aquella premisa que destaca la estructura estratificada de los sistemas jurídicos y en la cual la validez de las normas inferiores depende de su conformidad y adecuación a las superiores. El trabajo, intenta situarse dentro del no positivismo principialista en la Teoría del Derecho. Propone que en aquellos ordenamientos donde la noción de Dignidad Humana se incluya en la Carta Fundamental, normas tributarias del denominado Derecho Penal del Enemigo serían inconstitucionales. Se concluye reflexionando en torno a algunos rasgos de la formulación general del Derecho Penal del Enemigo que causarían tensiones irreconciliables con la noción de Dignidad Humana.

\section{Palabras clave}

Derecho Penal del Enemigo, Dignidad Humana, Neoconstitucionalismo, Garantismo, Constitucionalismo Contemporáneo.

\begin{abstract}
The article describes, without considering particular cases - and preferably by consulting the work of Günther Jakobs and some of his commentators - the main features of the

\footnotetext{
${ }^{1}$ Especialista en Constitucionalismo y Garantismo, Universidad de Castilla La Mancha. Magíster (C) en Derecho Público, Pontificia Universidad Católica de Chile. Se agradece la colaboración prestada en la redacción final de este trabajo a doña María Celeste Mora Escobar, profesora de la Facultad de Ciencias Jurídicas de la Universidad Andrés Bello, y a don Patricio Alvarez-Salamanca Moroso, alumno de la carrera de Derecho en la Universidad Alberto Hurtado. Sin la valiosa ayuda de ambos este trabajo no habría sido posible. Todo error en el producto que el lector tiene a su disposición es de exclusiva responsabilidad del autor. Se agradece también, en forma especial, al Dr. Eduardo Demetrio Crespo, docente del programa de Doctorado en Derecho de la Universidad de Castilla La Mancha, España.
} 
NUÑEZ LEIVA, José Ignacio. “Un análisis abstracto del Derecho Penal del Enemigo a partir del Constitucionalismo Garantista y Dignatario."

Criminal Law of the Enemy, abstractly. This, so as to evaluate their compatibility with the concept of Human Dignity, present in the majority of contemporary constitutional systems as well as in Human Rights protection systems. It is argued by applying the general statement, proposed by the theoretical neo constitutionalism, specially the principle that stresses the hierarchical structure of legal systems, in which the existence of a law depends of its compatibility and adequacy to higher laws. Through this work, we focus on the main non-positivism in the theory of law. It proposes that laws that recognize the Criminal Law of the Enemy, are unconstitutional if Human Dignity is included in the pertaining legal system's Constitution. It concludes reflecting about some features of Criminal Law of the Enemy, which cause irreconcilable issues with the concept of Human Dignity.

\section{Key words}

Criminal Law of the Enemy, Human Dignity, Neo constitutionalism, Contemporary constitutionalism.

\section{Introducción}

El presente trabajo tiene como propósito reflexionar en torno a la cada vez más difundida noción de Derecho Penal del Enemigo. Tal concepto, desde su aparición en el foro académico internacional, ha sido analizado críticamente de forma contundente por diversos y reputados autores. Las objeciones más difundidas al Derecho Penal del Enemigo suelen estar macadas por un sesgo teórico y moral - con total sinceridad, compartido también por nosotros - que tiende a sugerir su rechazo en virtud de su ineficiencia e incompatibilidad con la esencia del Derecho Penal.

Sin embargo, el análisis que realizaremos propone algo distinto. Se trata de una resistencia teórica ligada a la ciencia jurídica en general y en particular a las teorías del Derecho y de la Constitución. En efecto - y esto define la hipótesis central de nuestro trabajo - estimamos que en la actualidad la dinámica de los sistemas jurídicos se orienta por ciertos principios ligados a lo que ha dado en llamarse neoconstitucionalismo y garantismo, los cuales plantean - entre otras cosas - que el sistema jurídico se estructura de forma estratificada haciendo depender la validez de las normas inferiores de su compatibilidad y conformidad con las superiores. En dichos sistemas, producto de la presencia a nivel constitucional de normas de principios o con fuerte contenido axiológico, elementos propios de la moral crítica se insertan como agentes de racionalización de la producción normativa infraconstitucional. Uno de los principales criterios de este tipo, cuya presencia es posible constatar en gran parte de las constituciones vigentes, es el de la dignidad humana. En este contexto, que nos permitiría incluso hablar de un constitucionalismo garantista y dignatario, propuestas como el Derecho Penal de enemigo presentan notorias incompatibilidades con el concepto de dignidad humana y por tanto, en virtud de lo ya descrito, serían también inconstitucionales.

Para intentar confirmar nuestra hipótesis hemos estructurado este trabajo en base al siguiente itinerario. En primer lugar, enunciaremos, en abstracto, los principales rasgos del 
Polit. crim. Vol. 4, N 8 (Diciembre 2009), Art. 3, pp. 383-407 (1-25).

[http://www.politicacriminal.cl/Vol_04/n_08/Vol4N8A3.pdf]

Derecho Penal del Enemigo, luego, describiremos los perfiles más relevantes de la actual configuración de los sistemas jurídicos según lo propuesto por el neoconstitucionalismo y el garantismo, enunciando - de paso - algunas importantes consecuencias que se derivan de aquello. A continuación, constataremos la presencia del concepto dignidad humana en diversas constituciones e intentaremos precisar su rol y contenido. Después de ello, analizaremos algunas tensiones que se producen entre el ya citado concepto y el Derecho Penal del Enemigo. Concluiremos formulando algunas reflexiones.

\section{Perfiles del denominado Derecho Penal del Enemigo.}

Una de las características actuales ${ }^{2}$ del Derecho Penal - y por tanto de la política criminal de la que es tributario - consiste en su tendencia expansionista. En efecto, como lo sugiere Cancio Meliá, en el momento actual puede convenirse que el fenómeno más destacado en la evolución de las legislaciones penales del mundo occidental es la aparición de múltiples nuevas figuras, a veces incluso nuevos sectores de regulación, ello acompañado de una actividad de reforma de tipos penales ya existentes realizada a un ritmo muy superior al de épocas anteriores. ${ }^{3}$ Los rasgos centrales de dicha inclinación serían entre otros: la administrativización del Derecho Penal, esto es la reglamentación de nuevos sectores de la vida social eludiendo flagrantemente el principio de legalidad a través de la creación de delitos y penas por vía administrativa, la globalización del Derecho Penal, en tanto genera la intención de una persecución supranacional de la criminalidad de igual alcance, y la progresiva deconstrucción del paradigma liberal del Derecho Penal. ${ }^{4}$ Tal fenómeno, en el plano teórico, se traduce en un debate sobre la legitimidad del actual Derecho Penal ${ }^{5}$

\footnotetext{
${ }^{2}$ Aunque - siguiendo a Portilla Contreras - debiésemos hacer una previa distinción. Dicho autor nos sugiere que: "El sistema procesal penal contra la criminalidad organizada se ha caracterizado por una constante restricción de los principios básicos que rigen el tradicional funcionamiento tanto del Derecho Penal como del Derecho Procesal Penal, ergo al menos a nivel de reacción contra el crimen organizado el expansionismo del Derecho Penal no sería una tendencia reciente sino una constante.”. PORTILLAS CONTRERAS, Guillermo, "Fundamentos Teóricos del Derecho Penal y Procesal Penal del enemigo", Revista Jueces para la Democracia, $\mathrm{n}^{\circ} 49$ (2004), p. 43.

${ }^{3}$ CANCIO MELIÁ, Manuel, "Derecho penal del enemigo y delitos de terrorismo. Algunas consideraciones sobre la regulación de las infracciones en materia de terrorismo en el código penal español después de la LO/2000", Revista Jueces para la Democracia, $\mathrm{n}^{\circ} 44$ (2002), p. 19.

${ }^{4}$ DEMETRIO CRESPO, Eduardo, "Libertad, seguridad, sociedad del riesgo y Derecho Penal del Enemigo", en: BERNUZ BENÍTEZ, María José; PÉREZ, Ana Isabel (Coords.), La tensión entre libertad y seguridad, Universidad de la Rioja, 2006, p.113.

${ }^{5}$ En el mismo sentido Gracia Martín señala: "En los últimos años, la doctrina del Derecho penal dirige su mirada a ciertas regulaciones del Derecho positivo que parecen diferenciarse del Derecho penal general en virtud de determinadas características peculiares, las cuales motivarían o podrían motivar su agrupamiento e individualización como un particular corpus punitivo que podría identificarse con la denominación "Derecho penal del enemigo". Desde una perspectiva general, se podría decir que este Derecho penal del enemigo sería una clara manifestación de los rasgos característicos del llamado Derecho penal moderno, es decir, de la actual tendencia expansiva del Derecho penal que, en general, da lugar, formalmente, a una ampliación de los ámbitos de intervención de aquél, y materialmente, según la opinión mayoritaria, a un desconocimiento, o por lo menos a una clara flexibilización o relajación y, con ello, a un menoscabo de los principios y de las garantías jurídico-penales liberales del Estado de Derecho.". GRACIA MARTÍN, Luis, "Consideraciones críticas sobre el actualmente denominado "derecho penal del enemigo", Revista electrónica de ciencia penal y criminología, $\mathrm{N}^{\mathrm{o}} 7$ (2005), p. 2.
} 
marcado por una aparente dialéctica entre reduccionismo versus expansión ${ }^{6}$ en el cual las corrientes expansionistas se ven imbuidas por dos paradigmas a nivel de política criminal; el Derecho Penal Simbólico y un renovado punitivismo. ${ }^{7}$

Con el concepto Derecho Penal Simbólico nos referimos a aquella criminalización desproporcionada y oportunista, en muchos abiertamente pensada para no tener aplicación práctica, que se aparta de los fines tradicionales de la pena empleando a la sanción penal como un medio para transmitir a la población señales que den cuenta de la existencia de una autoridad estatal fuerte y decidida a reaccionar con firmeza en contra de aquellos actos reprobados por la mayoría..$^{8}$ En este sentido, el adjetivo "simbólico" asociado a este tipo de normas penales se identifica con la intencionalidad comunicativa insertada en la norma por el propio legislador interesado en demostrar firmeza mediante la criminalización como única política criminal. Por su parte, con la noción de punitivismo - específicamente con su reactivación como tendencia - hacemos alusión a la existencia de procesos caracterizados por la introducción de nuevas normas penales, ahora si pensadas para ser aplicadas, o el endurecimiento de las disposiciones ya vigentes - lo cual constituye una inversión del proceso de retroceso punitivo que se podía apreciar de manera sostenida durante el último tiempo - marcados por el hecho de que sus principales promotores ya no se diferencian ideológicamente ubicándose en la derecha política sino que provienen de todos los espectros del escenario político. En la criminalización de ciertas conductas recalcitrantemente conservadoras, como el racismo, la derecha política ha encontrado un espacio en el cual puede teñirse de un pretendido progresismo, mientras que, mediante la multiplicación y endurecimiento de las normas penales, la izquierda, resta protagonismo a sus adversarios políticos en el rol de asegurar el imperio de la ley y el orden en el Estado.'

En el Derecho Penal Simbólico la fuerza comunicativa de la norma se basa en la construcción de una categórica frontera que separa a los autores de las conductas criminalizadas y el resto de la sociedad. Para ello, es necesaria además la confluencia del punitivismo - sobretodo cuando se trata conductas respecto de las cuales la intervención legislativa consistió en el endurecimiento de las penas - de tal forma que ambas tendencias confluyen en una relación de dependencia mutua y de cuya combinación práctica surge el denominado Derecho Penal del Enemigo, ${ }^{10}$ propuesta teórica y normativa que durante el

\footnotetext{
${ }^{6}$ DEMETRIO CRESPO, Eduardo, "El "derecho penal del enemigo" darf nicht sein! Sobre la ilegitimidad del llamado "derecho penal del enemigo" y la idea de seguridad", Zeitschrift für Internationale Strafrechtsdogmatik, 9/2006, p. 431.

7 CANCIO MELIÁ, Manuel, "De nuevo ¿’Derecho Penal” del enemigo?”, en: CANCIO MELIÁ, Manuel; GÓMEZ-JARA DIEZ, Carlos (Eds.), Derecho Penal de Enemigo, el discurso penal de la exclusión, Vol. 1, D de F, 2006, p. 345.

8 Tanto un concepto más acabado como una contundente crítica al Derecho Penal Simbólico puede encontrarse en DÍEZ RIPOLLÉS, José Luis, "Derecho Penal Simbólico y los efectos de la pena", Boletín Mexicano de Derecho Comparado, No 103 (2002), p. 63 y ss.

${ }^{9}$ Manuel Cancio Meliá, al describir este fenómeno cita como ejemplo del mismo al denominado Código Penal Español de la Democracia (llamado así por su elaboración con posterioridad al reestablecimiento de la Democracia en España) el cual, si bien habría aportado en la superación de problemas dogmáticos presentes en su predecesor, en la práctica resultaría ser mucho más represivo que el anterior. MELIÁ, "De nuevo", cit. nota $\mathrm{n}^{\mathrm{o}} 7$, p. 357.

${ }^{10}$ CANCIO MELIÁ, Manuel, “¿”Derecho Penal” del Enemigo?”, en: JAKOBS, Günther; CANCIO MELIÁ, Manuel, Derecho Penal de Enemigo, Madrid: Editorial Thompson Civitas, 2003, p. 77.
} 
Polit. crim. Vol. 4, N 8 (Diciembre 2009), Art. 3, pp. 383-407 (1-25).

[http://www.politicacriminal.cl/Vol_04/n_08/Vol4N8A3.pdf]

último tiempo ha cobrado especial relevancia, colmando gran parte del foro académico de la especialidad. Sobre el particular Portilla Contreras expresa que lo novedoso no está constituido por la proliferación de prácticas de este tipo, sino por la aparición de un sustento doctrinal que las apoya. ${ }^{11}$

La compleja rúbrica Derecho Penal del Enemigo ${ }^{12}$ se construye a partir de una previa distinción estipulativa: ${ }^{13}$ la existencia de algunos sujetos que deben ser considerados como ciudadanos y la de otros que han de ser estimados y tratados como enemigos. A partir de ella, propone la configuración y vigencia de secciones del Derecho Penal inspiradas en paradigmas diversos. Una de ellas, el Derecho Penal del Ciudadano, define y sanciona delitos, o infracciones de normas, que llevan a cabo los ciudadanos de un modo incidental y que normalmente son la simple expresión de un abuso por los mismos de las relaciones sociales en que participan desde su status de ciudadanos, es decir, en su condición de sujetos vinculados a y por el Derecho. La otra, el Derecho Penal del Enemigo, configura y castiga actos de aquellos que habrían sido cometidos por individuos que en su actitud, en su vida económica o mediante su incorporación a una organización, se han apartado del Derecho presumiblemente de un modo duradero y no sólo de manera incidental, y por ello, no garantizan la mínima seguridad cognitiva de un comportamiento personal y demostrarían este déficit por medio de su comportamiento. ${ }^{14}$

Tal distinción se construye a partir del siguiente razonamiento: El fin del Estado de Derecho, nos sugiere Jakobs, ${ }^{15}$ no consiste en alcanzar la mayor seguridad posible para los bienes, sino en la efectiva y real vigencia del ordenamiento jurídico. Sólo ello hace posible la libertad. La vigencia real del Derecho contrasta con su vigencia postulada. En el primero de los casos, las normas efectivamente funcionan como prescripciones que orientan el comportamiento de sus destinatarios, proveyendo certeza jurídica, en el segundo, no existe

${ }^{11}$ PORTILLA CONTRERAS, Guillermo, "Fundamentos Teóricos del Derecho Penal y Procesal Penal del Enemigo", Revista Jueces para la Democracia, № 49, p. 43.

${ }^{12}$ El concepto de Derecho Penal del Enemigo fue introducido en el debate por Günther Jakobs a partir de una primera fase en un congreso celebrado en Frankfurt en el año 1985, en el contexto de una reflexión sobre la tendencia en Alemania hacia la "criminalización en el estadio previo a una lesión" del bien jurídico. En esta ponencia, Jakobs manifiesta la necesidad de separar en caso excepcional al Derecho penal del enemigo del Derecho penal de los ciudadanos con el fin de conservar el Estado liberal; tesis que en aquél momento no tuvo mayor trascendencia. Y es, a partir del Congreso de Berlín de 1999 que surge una segunda fase orientada hacia delitos graves contra bienes jurídicos individuales. Diferente fue la reacción crítica entre los juristas alemanes después de la intervención de Jakobs en este Congreso, principalmente por la diferenciación que el autor propone entre el Derecho penal del ciudadano dirigido a personas y el Derecho penal del enemigo destinado a no personas y que es, según Jakobs, necesario para combatir por ejemplo el terrorismo. VÍQUEZ, Karolina, "Derecho penal del enemigo ¿Una quimera dogmática o un modelo orientado al futuro?", Polit. crim. $\mathrm{N}^{\mathrm{o}} 3$ (2007), p. 2.

${ }^{13}$ Aunque Jakobs es insistente en señalar que su teoría parte de una observación al comportamiento y tendencia actual del Derecho Penal, siendo por tanto descriptiva, es insoslayable el deber ser envuelto en ella, lo cual la convierte en estipulativa. Sobre el particular véase lo señalado por FERRAJOLI, Luigi, "El derecho penal del Enemigo y la disolución del Derecho Penal", en: CARBONELL, Miguel (Ed.), Luigi Ferrajoli: Democracia y Garantismo, Madrid: Editorial Trotta, 2008, p 236.

${ }^{14}$ GRACIA MARTÍN, “Consideraciones críticas”, cit. nota n 5, p. 6.

${ }^{15}$ Lo siguiente constituye una síntesis del razonamiento presentado por el citado autor en: JAKOBS, Günther, “¿Terroristas como personas en Derecho?”, en: CANCIO MELIÁ, Manuel; GÓMEZ-JARA DIEZ, Carlos (Eds.), Derecho Penal de Enemigo, el discurso penal de la exclusión, Vol. 2, D de F, 2006, p. 80. 

partir del Constitucionalismo Garantista y Dignatario."

tal orientación y, por tanto, tampoco certeza jurídica ni seguridad para la libertad. La vigencia real del Derecho - en opinión del jurista alemán - resiste contravenciones, en tanto estas sean consideradas como tales, mediante el empleo de la sanción como reafirmación de la vigencia del Derecho. Formaría entonces, parte de la vigencia real del Derecho, la existencia de un apoyo cognitivo de las normas, esto es la disposición interna de los sujetos normativos a su cumplimiento y la comunión de aquellos con las valoraciones portadas por la norma manifestada en la ponderación positiva de los bienes protegidos por el Derecho.

El apoyo cognitivo no constituye una prestación estatal sino de los sujetos normativos y sin su presencia se diluye la expectativa de vigencia real contenida en toda norma. En este contexto, las contravenciones eventuales de la norma no implican una negación general y generalizada de la vigencia del Derecho ni configuran, necesariamente, una presunción de que el infractor ha renunciado de forma irrevocable al comportamiento conforme a Derecho.

Sin embargo, la expectativa de comportamientos correctos no puede ser mantenida de manera indefinida ante la evidencia de sostenidas y profundas contravenciones. ${ }^{16}$ Por el contrario - afirma categóricamente el catedrático emérito de la Universidad de Bonn - el Estado no debe insistir ilimitadamente en la expectativa de cumplimiento ante contravenciones sostenidas puesto que debe ocuparse de la vigencia real del Derecho, por lo que ha de proceder contra los quebrantamientos del Derecho cuya próxima comisión se percibe.

En este contexto, sería posible distinguir entre diversas categorías de sujetos normativos: unos respecto de los cuales una contravención no desvirtúa la expectativa de comportamiento futuro conforme a Derecho y otros cuyas contravenciones si lo hacen. Ello supone además, que existiría una especie de confianza depositada por el Estado en el sujeto en orden a presumir su voluntad de permanecer bajo el amparo y vigencia del Derecho. Sin embargo, sería responsabilidad de cada individuo mantener dicha presunción a su favor mediante un habitual e incontrovertible comportamiento conforme a Derecho. ${ }^{17}$

Tal razonamiento, impacta profundamente en el concepto de persona y más específicamente en su fundamento y en la finalidad asignada a la sanción penal. Para la línea argumental en análisis, la noción de persona descansa en una base positiva, contractualista y utilitarista, ${ }^{18}$ no responde a un postulado ontológico, sino a la confluencia

\footnotetext{
${ }^{16}$ Afirmando aquello, en otros pasajes de su obra Jakobs ha argumentado de la siguiente forma: "Las personas no quieren tener derecho, sino también salir adelante con su cuerpo, es decir, sobrevivir en cuanto individuos necesitados", y la confianza en lo que no debe ser sólo supone una orientación con la que es posible sobrevivir cuando no es contradicha con demasiada intensidad por el conocimiento de lo que será.". JAKOBS, Günther, "Derecho penal del Ciudadano y Derecho Penal del Enemigo", en: JAKOBS/CANCIO MELIÁ, Derecho Penal de Enemigo, cit. nota ${ }^{\circ} 10$, p. 37.

${ }^{17}$ JAKOBS, Günther, “¿Derecho penal del enemigo? Un estudio acerca de los presupuestos de la juridicidad”, en: CANCIO MELIÁ/ GÓMEZ-JARA DIEZ (Eds.), Derecho Penal de Enemigo, cit. nota n 15 , p. 96.

18 "La reacción del ordenamiento jurídico frente a esta criminalidad se caracteriza, de modo paralelo a la diferenciación de KANT entre estado de ciudadanía y estado de naturaleza acabada de citar, por la circunstancia de que no se trata en primera línea de la compensación de un daño a la vigencia de la norma, sino de la eliminación de un peligro: la punibilidad se adelanta un gran trecho hacia el ámbito de la
} 
Polit. crim. Vol. 4, N 8 (Diciembre 2009), Art. 3, pp. 383-407 (1-25).

[http://www.politicacriminal.cl/Vol_04/n_08/Vol4N8A3.pdf]

de ciertas condiciones, entre ellas, un compromiso de fidelidad al ordenamiento jurídico y, mediante él, al contrato social. Quién no lo manifiesta, no sería persona ni ciudadano, sino enemigo, es decir, no persona. Y las penas con que se los sanciona no han de tener como finalidad reafirmar la vigencia del Derecho sino asegurarla mediante la neutralización de la fuente de peligro: el enemigo.

Según el propio Jakobs, gestor de la rúbrica Derecho Penal del Enemigo, este se caracterizaría por los siguientes rasgos: ${ }^{19}$ un amplio adelantamiento de la punibilidad caracterizado porque la visión retrospectiva del sistema punitivo ha sido reemplazada por una lógica prospectiva, por un aumento de la magnitud de las penas en contraste con el derecho penal "de ciudadanos" - desproporcionalidad en las penas- ${ }^{20}$ por la disminución e incluso supresión de las garantías procesales individuales ${ }^{21}$ (esto último incluso hace hablar a algunos de un Derecho Procesal Penal de Enemigo), y por - siendo esta una característica propuesta por Luis Gracia Martín - , el surgimiento de un segmento especial del Derecho Penitenciario, destinado a ser aplicado en contra de los destinatarios del Derecho Penal del Enemigo $^{22}$.

La aplicación práctica de esta tendencia, a veces, se distingue mediante las elocuentes denominaciones de algunas leyes: "Leyes de combate contra el terrorismo", "Leyes de lucha contra el tráfico de drogas". En otros casos, es el propio contenido de las normas lo que muestra su filiación al Derecho Penal del Enemigo. Lamentables ejemplos de ello son: la denominada Patriot Act de los Estados Unidos de América, de 26 de octubre de 2001 y la Anti Terrorism, crime and security Bill, de Inglaterra, de 14 de diciembre de 2001. En virtud de la primera, se autorizan acciones y medidas tales como la intervención y escucha de comunicaciones telefónicas y electrónicas, registros domiciliarios secretos, la derogación del secreto que envuelve la relación abogado-cliente, la imposición de censura, el juzgamiento de sospechosos en forma secreta, la facultad presidencial de definir que una persona sea juzgada por tribunales militares, la privación del derecho del acusado a elegir un abogado, la posibilidad de que la presunción de inocencia sea desvirtuada por pruebas

preparación, y la pena se dirige hacia el aseguramiento frente a hechos futuros, no a la sanción de hechos cometidos. Brevemente: la reflexión del legislador es la siguiente: el otro «me lesiona ya por... [su] estado [en ausencia de legalidad] (statu iniusto), que me amenaza constantemente). Una ulterior formulación: un individuo que no admite ser obligado a entrar en un estado de ciudadanía no puede participar de los beneficios del concepto de persona. Y es que el estado de naturaleza es un estado de ausencia de normas, es decir, de libertad excesiva tanto como de lucha excesiva. Quien gana la guerra determina lo que es norma, y quien pierde ha de someterse a esa determinación.". JAKOBS, Günther. "Derecho penal del Ciudadano y Derecho Penal del Enemigo", en: JAKOBS/CANCIO MELIÁ, Derecho Penal de Enemigo, cit. nota n 10, p. 41.

19 JAKOBS, Günther, "La ciencia del Derecho Penal ante las exigencias del presente", Estudios de Derecho Judicial, No 20 (1999), pp. 119-146

${ }^{20}$ GRACIA MARTÍN, Luis, El horizonte del finalismo y el Derecho Penal del Enemigo, Valencia: Editorial Tirant Lo Blanch, 2005, p 109.

${ }^{21}$ En tal descripción coinciden, entre otros: CANCIO MELIÁ, "De nuevo", cit. nota n. 7, p. 357, FEIJOO SÁNCHEZ, Bernardo, "El Derecho Penal del Enemigo y el Estado Democrático de Derecho", en: CANCIO MELIÁ/ GÓMEZ-JARA DIEZ, (Eds.), Derecho Penal de Enemigo, cit. nota n ${ }^{\circ}$ 7, p. 802, CALLEGARI, André; DUTRA, Fernanda, "Derecho Penal del Enemigo y Derechos Fundamentales", en: CANCIO MELIÁ/ GÓMEZ-JARA DIEZ, (Eds.), Derecho Penal de Enemigo, cit. nota n 7, p. 329. DEMETRIO, "El "derecho penal del enemigo", cit. nota n 6, y GRACIA MARTÍN, El horizonte del finalismo, cit. nota n 20, p 110.

${ }^{22}$ GRACIA MARTÍN, El horizonte del finalismo, cit. nota ${ }^{\circ} 20, \mathrm{p} 112$. 
NUÑEZ LEIVA, José Ignacio. “Un análisis abstracto del Derecho Penal del Enemigo a partir del Constitucionalismo Garantista y Dignatario."

que tengan "un peso razonable", el ocultamiento de pruebas de cargo de la defensa por razones de seguridad nacional, la improcedencia de impugnación de las sentencias condenatorias ante tribunales de alzada sino sólo ante el secretario de Defensa. ${ }^{23}$

\section{Funcionamiento del sistema jurídico según los paradigmas neoconstitucional y garantista.}

\subsection{Neoconstitucionalismo.}

La labor de precisar las diferencias entre las rúbricas "constitucionalismo contemporáneo" y "neoconstitucionalismo" puede resultar agotadora y es sin duda compleja. ${ }^{24} \mathrm{Su}$ dificultad deriva - entre otras causas - de que, bajo el nombre neoconstitucionalismo(s), se suele agrupar a una serie de propuestas, a veces, muy distintas entre sí. ${ }^{25}$ Sobre el particular, Bernal Pulido, nos recuerda que desde su utilización inicial por Pozzolo, ${ }^{26}$ el concepto neoconstitucionalismo ha sido usado como cajón de sastre para referirse de un lado, a algo ya conocido, el constitucionalismo europeo contemporáneo o constitucionalismo de la posguerra, y de otro, para enmarcar las ideas de autores de variadas tendencias. ${ }^{27}$ Entre ellos podrían citarse a Mac Cormick, Raz, Alexy, Nino $^{28}$ y Ferrajoli. ${ }^{29}$ Por esta razón sería difícil hablar de una versión estándar de neoconstitucionalismo.

Sin embargo, al menos en el plano teórico, el constitucionalismo contemporáneo y los neoconstitucionalismos comparten el afán por describir y destacar los logros de la constitucionalización, es decir, de aquel proceso causado por una revitalizada Constitución

\footnotetext{
${ }^{23}$ CASTRESANA FERNÁNDEZ, Carlos, "Guerra al terror y derecho", Revista Jueces para la Democracia, No 43 (2002), p. 6.

${ }^{24}$ PRIETO SANCHÍS, Luis, Justicia constitucional y derechos fundamentales, Madrid: Editorial Trotta, 2003, p. 101.

${ }^{25}$ Este es un término de reciente incorporación al léxico académico que tanto puede referirse al tipo de constituciones que han prosperado en la Europa de posguerra, como a ciertas doctrinas o concepciones sobre el Derecho; aunque en este último caso las tesis que se califican de neoconstitucionalista no son en modo alguno uniformes e incluso a veces resultan opuestas. Vid. POZZOLO, S., Neocostituzionalismo e positivismo giuridico, Torino: Ed. Giappichelli, 2001; COMANDUCCI, P., "Forme di (neo)costituzionalismo: una ricognizione metateorica", en: T. MAZZARESE (Ed.), Neocostituzionalismo e tutela (sovra)nazionale dei diritti fondamentali, Torino: Ed. Giappichelli, 2002, pp. 71 y ss; y en este mismo volumen, MAZZARESE T., "Diritti fondamentali e neocostituzionalismo: un inventario di problemi", pp. 7 y ss. PRIETO SANCHÍS, Luis, "La teoría del Derecho en Principia Iuris", Conferencia pronunciada en la IX Edición de los cursos de post grado en Derecho de la Universidad de Castilla La Mancha, Toledo, España. 2009. Inédito, p. 9.

${ }^{26}$ Véase POZZOLO, S, "Neoconstitucionalismo y especificidad de la interpretación constitucional", Doxa, No 21 (1998), p. 339 y ss.

${ }^{27}$ BERNAL PULIDO, Carlos, "Refutación y defensa del neoconstitucionalismo", en: CARBONELL, Miguel (Ed.), Teoría del neoconstitucionalismo, ensayos escogidos, Madrid: Editorial Trotta, 2007, p.301.

${ }^{28}$ PRIETO SANCHÍS, Luis, "Replica a Juan Antonio García Amado", en: CARBONELL (Ed.), Teoría del neoconstitucionalismo, cit. nota $\mathrm{n}^{\circ} 27$, p.265.

${ }^{29}$ Aunque en estricto rigor las tesis de Ferrajoli, quien se define a si mismo como positivista, se apartan en ciertos sentidos de los neoconstitucionalismos. Sobre el particular véase: PRIETO SANCHÍS, Luis, "La teoría del Derecho en Principia Iuris", cit. nota n 25.
} 
Polit. crim. Vol. 4, N 8 (Diciembre 2009), Art. 3, pp. 383-407 (1-25).

[http://www.politicacriminal.cl/Vol_04/n_08/Vol4N8A3.pdf]

que ha ocasionado una modificación de los sistemas jurídicos respecto de lo existente antes del despliegue del proceso mismo ${ }^{30}$ y que deviene en el Estado Constitucional de Derecho.

Según Prieto Sanchís, estos conceptos, sirven para designar un modelo teórico, pero también para referirse a una forma de organización política que se viene abriendo paso desde mediados del siglo XX, que no necesariamente reúne en todas sus manifestaciones signos de uniformidad, pero si unos rasgos esenciales que permiten hablar de algo diferente, no radicalmente nuevo, pero si distinto a lo que pudo representar el Estado de Derecho decimonónico. ${ }^{31}$

El cambio mencionado se produce a partir de la introducción de conceptos como el valor normativo de la Constitución y la vinculación de la jurisdicción a los Derechos Fundamentales. $^{32}$ Ello es el corolario de la fusión de dos tradiciones, la de las constituciones materiales; aquellas que presentan un denso contenido sustantivo integrado por normas de diferente valoración (valores, principios, derechos, directrices) y las constituciones garantizadas, caracterizadas porque su protección o efectividad se encomienda a jueces $\mathrm{o}$, si se prefiere, en su sistema existen normas secundarias, de organización y procedimiento, destinadas a depurar o sancionar toda infracción de las normas sustantivas o relativas a derechos. Así la Constitución se convierte en límite y norma directiva fundamental. Frente al rousseauniano poder constituyente que nunca termina de constituirse - nos dice Prieto - y que desemboca en la superioridad del parlamento y de su ley - lógica básica de los sistemas de raíz francesa - el poder constituyente toma cuerpo en un texto jurídico supremo, válido, vigente y garantizado. ${ }^{33}$ Todo lo anterior, agregaría Manuel Aragón, ha sido producto de adicionar al concepto liberal de constitución la impronta social y democrática de Derecho reconociendo su valor de norma jurídica. ${ }^{34}$

El resultado de esta combinación, señala con contundencia Ferrajoli, es un nuevo modelo de Derecho y Democracia: el Estado Constitucional de Derecho, que es fruto de un verdadero cambio de paradigma respecto al modelo paleopositivista del Estado Legislativo de Derecho ${ }^{35}$ y en el cual, siguiendo la clasificación de Guastini, la Constitución es fuente del Derecho en un triple sentido: primero, por contener normas, segundo, por disponer parámetros sustantivos y procedimentales para abrogar y/o invalidar normas inferiores preconstitucionales e invalidar normas posteriores que la contravengan, y tercero - siendo quizás esto lo más destacable - por entenderse que las normas constitucionales son idóneas para disciplinar directamente no sólo la organización estatal y las relaciones entre el Estado

30 COMANDUCCI, Paolo, "Formas de (Neo) Constitucionalismo: Un análisis metateórico", Revista Isonomía, No 16 (2002), p 97.

${ }^{31}$ PRIETO, Justicia constitucional, cit. nota ${ }^{\circ} 24$, p. 107.

32 JULIO ESTRADA, Alexei, "Los tribunales constitucionales y la eficacia entre particulares de los derechos fundamentales”, en: CARBONELL (Ed.), Teoría del neoconstitucionalismo, cit. nota n²7, p. 148.

${ }^{33}$ PRIETO SANCHÍS, Luis, "El constitucionalismo de los derechos", en: CARBONELL (Ed.), Teoría del neoconstitucionalismo, cit. nota $\mathrm{n}^{\circ} 27$, p. 214.

34 ARAGÓN REYES, Manuel, "La constitución como paradigma”, en: CARBONELL (Ed.), Teoría del neoconstitucionalismo, cit. nota $\mathrm{n}^{\circ} 27$, p. 35 .

35 FERRAJOLI, Luigi, "Sobre los derechos fundamentales", en: CARBONELL (Ed.), Teoría del neoconstitucionalismo, cit. nota $\mathrm{n}^{\circ} 27, \mathrm{p} .71$. 
NUÑEZ LEIVA, José Ignacio. “Un análisis abstracto del Derecho Penal del Enemigo a partir del Constitucionalismo Garantista y Dignatario."

y las personas, sino también las que ocurran entre estas últimas, y son por tanto susceptibles de ser aplicadas por cualquier juez y no solo por el juez constitucional. ${ }^{36}$

El valor normativo de la Constitución como concepto fundante de los neoconstitucionalismos produce una serie de consecuencias relevantes, entre ellas, Alexy destaca: la sustitución de las reglas por los principios como elementos protagónicos del Derecho, la necesariamente consecuente utilización de la técnica de la ponderación en desmedro de la subsunción para la aplicación de las normas, la omnipresencia de la Constitución en lugar de la independencia del derecho infraconstitucional y el fortalecimiento del poder de la judicatura en perjuicio de las facultades del legislador. ${ }^{37}$

Todo lo anterior claramente altera el paradigma decimonónico del Estado de Derecho y afecta las bases del sistema de fuentes elaborado a su amparo, las de su teoría constitucional y del derecho, y su concepto de democracia.

Con respecto al sistema de fuentes, la Constitución irrumpe como fuente del Derecho en el sentido pleno de la expresión, es decir, como origen inmediato de derechos y obligaciones, y no solo como fuente de las fuentes. ${ }^{38}$ Ello altera la relación Constitución - Ley. De una dinámica en la cual los derechos y obligaciones contenidos en la Constitución adquirían fuerza en tanto eran desarrollados por la ley, se pasa a una relación de subordinación en donde - en palabras de Susanna Pozzolo - la ley opera como un mero factor de mediación entre las exigencias constitucionales y las exigencias prácticas. ${ }^{39}$ Lo cual, de paso, nos obliga además a repensar el principio dinámico con el que por tanto tiempo se caracterizó el sistema jurídico, pues la innovación por parte de normas subconstitucionales, de acuerdo a esta nueva lógica, es válida en tanto su contenido sea deudor de los principios y valores contenidos en la Constitución, rasgo propio de los sistemas estáticos. ${ }^{40}$

En lo relativo a la teoría constitucional, las relaciones recíprocas entre las funciones del Estado se alteran sustantivamente. El esquema decimonónico en el cual el legislador se encuentra investido con la capacidad de representar a la soberanía y por tanto invocar su inviolabilidad, resulta alterado por la aparición de una jurisdicción, ya sea ordinaria o específicamente constitucional, capaz de oponerse al contenido sustancial de sus decisiones, sea impidiendo que se conviertan en Derecho vigente o suprimiéndolas del sistema jurídico con efecto general o particular según sea el caso, encargada de un continuo adecuamiento de la legislación a la Constitución mediante la tutela de las exigencia de la justicia sustancial en cada caso concreto y que se erige como el principal agente

${ }^{36}$ GUASTINI, Ricardo, "Sobre el concepto de Constitución", en "Sobre los derechos fundamentales", en: CARBONELL (Ed.), Teoría del neoconstitucionalismo, cit. nota $\mathrm{n}^{\circ}$ 27, p.22.

${ }^{37}$ ALEXY, Robert, El concepto y la validez del Derecho, Barcelona: Editorial Gedisa, 1994, p. 160.

38 RUBIO, F., "La constitución como fuente del Derecho, en La Constitución española y las fuentes del Derecho", Instituto de Estudios Fiscales, Vol. 1 (1979), p. 62., citado por PRIETO SANCHÍS, Luis, Constitucionalismo y positivismo, México: Editorial Fontamara, 1997. p 17.

${ }^{39}$ POZZOLO, Sussana, "Neoconstitucionalismo y especificidad de la interpretación constitucional", Doxa, No 21 (1998), p. 341.

${ }^{40}$ GARCÍA FIGUEROA, Alfonso, Principios y positivismo jurídico, El no positivismo principialista en las teorías de Ronald Dworkin y Robert Alexy, Madrid: Centro de Estudios Políticos y Constitucionales, 1998, p 62. 
Polit. crim. Vol. 4, N 8 (Diciembre 2009), Art. 3, pp. 383-407 (1-25).

[http://www.politicacriminal.cl/Vol_04/n_08/Vol4N8A3.pdf]

racionalizador del sistema jurídico. ${ }^{41}$ Una función muy difícil de encuadrar en la formulación tripartita de la separación de poderes, e incluso en ciertos casos contramayoritaria.

Por su parte, la democracia operativa dentro del paradigma paleopositivista - citando a Ferrajoli - se ha convertido en Democracia constitucional. Este es un modelo que no se limita a programar solo las formas de producción del Derecho mediante norma procedimentales sino que además programa sus contenidos. Está constituido por normas metalegales que disciplinan la máxima expresión de las mayorías contingentes presentes en el proceso de generación de las leyes. En síntesis, la Constitución es aquel Derecho por sobre el derecho y opera como una convención sobre el coto vedado ${ }^{42}$ o acerca de lo que es indecidible para cualquier mayoría. ${ }^{43}$

La constitucionalización rígida de los Derechos Fundamentales - nos sugiere el célebre jurista de Florencia - impone obligaciones y prohibiciones a los poderes públicos y ha insertado en la democracia una dimensión sustancial. Si las normas formales de la Constitución, esto es aquellas que disciplinan la organización de los poderes públicos, aseguran la dimensión formal de la democracia política, aquellas que establecen los principios y Derechos Fundamentales garantizan lo que se puede denominar democracia sustancial, y se refieren a qué no puede ser decidido o debe ser decidido por toda mayoría, vinculando toda la legislación bajo pena de invalidez a los derechos, principios y valores fundamentales. Ello cambia también la relación entre Derecho y Política, pues ya no es el primero quien se subordina a la segunda, sino a la inversa. ${ }^{44}$

\subsection{Garantismo.}

Como bien afirma Santiago Sastre, el término "garantía" es quizás uno de los más empleados por el lenguaje jurídico. En un sentido amplio, y distinguiéndolo debidamente de los objetos protegidos, podemos entender que con el concepto garantía se alude a los instrumentos o medios mediante los cuales el Derecho protege y tutela dicho bien o valor ${ }^{45}$ o más específicamente a las técnicas de tutela de los Derechos Fundamentales. ${ }^{46}$

Con el concepto Garantismo, por su parte, según la distinción efectuada por Ferrajoli en su conocida opera prima Derecho y Razón, teoría del garantismo penal, se puede aludir a tres nociones distintas, pero vinculadas entre sí.

En primer lugar, a un modelo normativo de Derecho, constituido por un sistema de poder mínimo dotado de técnicas de tutela capaces de minimizar la violencia y maximizar la

\footnotetext{
${ }^{41}$ POZZOLO, Neoconstitucionalismo, cit. nota $\mathrm{n}^{\mathrm{o}}$ 39, p. 342.

${ }^{42}$ GARZÓN VALDÉS, Ernesto, “Algo más acerca del coto vedado”, Doxa, N o 6 (1989), p. 209.

${ }^{43}$ FERRAJOLI, Luigi, Derecho y razón. Teoría del garantísmo penal. Madrid: Editorial Trotta, p. 858.

${ }^{44}$ FERRAJOLI, Luigi, La democracia constitucional, en: CARBONELL (Ed.), Luigi Ferrajoli: Democracia $y$ Garantismo, cit. nota $\mathrm{n}^{\circ} 13$, p. 32 .

${ }^{45}$ SASTRE ARIZA, Santiago, "Derecho y Garantías", Jueces para la Democracia N 38 (2000), p. 3.

${ }^{46}$ FERRAJOLI, Luigi. "Garantías", en: CARBONELL (Ed.), Luigi Ferrajoli: Democracia y Garantismo, CARBONELL, cit. nota $\mathrm{n}^{\circ} 13$, p. 60.
} 
NUÑEZ LEIVA, José Ignacio. “Un análisis abstracto del Derecho Penal del Enemigo a partir del Constitucionalismo Garantista y Dignatario."

libertad y que en el ámbito jurídico genera un sistema de vínculos impuestos a la potestad punitiva del Estado, apreciable no por su presencia absoluta sino por el grado en que se satisfacen los fines mencionados. En el ámbito constitucional - por ejemplo - se dirá que un sistema es más o menos garantista en tanto cuente con mecanismos de invalidación y reparación idóneos para asegurar la efectividad de los derechos normativamente proclamados.

En segundo lugar, designa a una teoría crítica del Derecho cuya misión consiste en denunciar la existencia de divergencias empíricas entre el ser y el deber ser de los ordenamientos jurídicos complejos a raíz de los contrastes existentes entre sus modelos y sus prácticas concretas.

Y en tercer lugar, alude a una filosofía del Derecho - motivada por la desconfianza en el poder $^{47}$ - en virtud de la cual se endosa al Derecho y al Estado el deber de justificación externa conforme a los bienes e intereses cuya tutela y garantía constituye precisamente su finalidad. ${ }^{48}$

Estos tres significados delinean la teoría general del garantismo como proyecto que constituye la otra cara del constitucionalismo, pues este último establece imperativos sustanciales al derecho positivo mediante la positivación constitucional del deber ser. ${ }^{49} \mathrm{El}$ garantismo no encontrará un espacio de desarrollo tan propicio bajo los paradigmas opuestos al Estado constitucional, y el constitucionalismo precisa del proyecto garantista para condicionar la legitimidad del poder al cumplimiento de las exigencias de los Derechos Fundamentales, pues ambos comparten el reconocimiento de la existencia de un Derecho superior metalegal, que reside en las constituciones, la visión sustancial de la democracia y la idea de evaluar la validez de las normas infraconstitucionales según criterios formales y materiales.

El aporte que el garantismo hace al constitucionalismo contemporáneo y a los neoconstitucionalismos - en definitiva al Estado - consiste en la actitud que promueve en la ciencia jurídica, defendiendo una concepción del Estado como instrumento al servicio de la protección de los Derechos, y del cientista jurídico, no como mero observador acrítico de aquello que ocurre en los distintos estratos jurídicos, sino como sagaz perseguidor de los desajustes entre el deber ser y el ser del Derecho, entre el horizonte de valores propuesto por la Constitución y el comportamiento de los operadores jurídicos, empezando por el legislador que con frecuencia frustra o desatiende dicho horizonte. Empero, el garantismo no se satisface con la mera denuncia sino que requiere además la búsqueda de soluciones mediante el empleo de las garantías actualmente disponibles en el propio ordenamiento jurídico o, si estas son insuficientes, el diseño de nuevas garantías que permitan colmar la laguna causada por la existencia de una norma constitucional insuficientemente garantizada. $^{50}$

\footnotetext{
${ }^{47}$ FERRAJOLI, Garantías, cit. nota ${ }^{\circ}$ 46, p. 62.

${ }^{48}$ FERRAJOLI, Derecho y razón, cit. nota n ${ }^{\circ} 43$, p. 853.

${ }^{49}$ FERRAJOLI, Luigi, Garantismo, una discusión sobre Derecho y democracia, Madrid: Editorial Trotta, 2006, p. 16.

${ }^{50}$ PRIETO, Justicia constitucional, cit. nota no 24, p.106.
} 
Polit. crim. Vol. 4, N 8 (Diciembre 2009), Art. 3, pp. 383-407 (1-25).

[http://www.politicacriminal.cl/Vol_04/n_08/Vol4N8A3.pdf]

Lo anterior corresponde a lo que Ferrajoli denomina la aporía de la irreductible ilegitimidad jurídica de los poderes públicos - idea que suprime definitivamente, al menos en el plano de la teoría constitucional, la noción de soberanía como categoría infalible - la cual se distingue mediante la constatación de la incorporación de deberes públicos en el derecho positivo, mediante la constitucionalización de los Derechos Fundamentales y de valores y principios, los que por su naturaleza deóntica, en el caso de los primeros, contienen la posibilidad de ser violados, y en el caso de valores y principios, la imposibilidad practica de ser íntegramente realizados o satisfechos. ${ }^{51}$

En suma - y en palabras de Ferrajoli, estandarte del paradigma en análisis - el garantismo concibe al Estado como un sistema constitucionalmente preordenado a la tutela de los Derechos Fundamentales, en el que la legalidad no es solo condicionante, sino que está también condicionada por vínculos jurídicos formales y sustanciales. Un sistema de esta clase, atento vigilante y preciso depurador del Derecho ilegítimo, es un sistema garantista.

En un orden de esta naturaleza, la judicatura adquiere un nuevo rol, desconocido por el Estado legal de Derecho. Los desniveles entre normas, que están en la base de la existencia de las normas inválidas, y por otra parte la incorporación de los Derechos Fundamentales en el nivel constitucional, cambian la relación entre juez y ley, y asignan a la jurisdicción una función de garantía al ciudadano frente a las violaciones de cualquier nivel de la legalidad por parte de los poderes públicos. ${ }^{52}$

Así, desde una perspectiva garantista, la estructura normativa de los Estados constitucionales de Derecho se caracteriza por la pertenencia de las normas vigentes a diversos planos (constitucional, legal, reglamentario, etc.) jerárquicamente ordenados, cada uno de los cuales se configura como normativo respecto del inferior, y como fáctico en relación al superior. ${ }^{53}$ Lo cual evidencia el sometimiento absoluto de toda fuente de producción normativa al nivel superior de normas, especialmente a la Constitución. En dicho contexto las prescripciones contenidas en normas superiores condicionan la validez de las normas inferiores, y el cumplimiento de aquellas, define la eficacia de las normas superiores, lo cual rompe, de paso, con la paleopositivista confusión entre validez y vigencia de las normas.

\section{Dignidad Humana en el Estado Constitucional Garantista (y Dignatario).}

Como ya pudimos precisar, una de las notas distintivas de la estructura actual de los sistemas jurídicos ha sido la irrupción de un denso contenido axiológico por la vía de las normas de principios. Cuestión constatada por los neoconstitucionalismos, no positivistas o directamente iusnaturalistas, e incluso por el garantismo, tendencia abiertamente neopositivista.

\footnotetext{
${ }^{51}$ FERRAJOLI, Derecho y razón, cit. nota n ${ }^{\circ} 43$, p. 866.

52 FERRAJOLI, Luigi, "El derecho como sistema de garantías" en: Derechos y garantías. La ley del más débil, Madrid: Editorial Trotta, 2004, p. 19.

53 SERRANO, José Luis, Validez y Vigencia, La aportación garantista a la teoría de la norma jurídica, Madrid: Editorial Trotta, 1999, p. 59.
} 
NUÑEZ LEIVA, José Ignacio. "Un análisis abstracto del Derecho Penal del Enemigo a partir del Constitucionalismo Garantista y Dignatario."

Probablemente el valor de nivel constitucional que cuya presencia se puede verificar con mayor frecuencia en los ordenamientos jurídicos contemporáneos es el de la Dignidad Humana, hecho que nos sugeriría la necesidad de completar la rúbrica descriptiva de los sistemas jurídicos actuales el Estado Constitucional Garantista adicionando el calificativo dignatario. Tal como lo sostiene María Cristina Fix Fierro, luego de la segunda guerra mundial se inauguró una nueva época en la cual la convivencia de los pueblos se cimentó en el respeto de la dignidad de todas las personas. En el constitucionalismo de dicha etapa la dignidad humana se eleva a la categoría de núcleo axiológico constitucional y, por tanto, de valor jurídico supremo. ${ }^{54}$

En efecto, como lo ha verificado Aldunate Lizana - entre otros - podemos encontrar normas constitucionales que promueven la Dignidad Humana en: el artículo $1^{\circ}$ de la Ley Fundamental de Bonn, en el artículo $1^{\circ}$ de la Constitución de Portugal, en el 10.1 de la Constitución Española, en el artículo $1^{\circ}$ de Constitución de Brasil y en el artículo primero de las Constituciones de Colombia, Chile y Perú, ${ }^{55}$ entre otras. ${ }^{56}$ Tal acontecimiento - y en esto coincidimos con lo enunciado por el ya citado autor - permite, junto con eludir la monumental tarea de precisar un fundamento filosófico externo de los Derechos Fundamentales, ensayar una construcción dogmática a partir de las normas positivas fundantes que tienda a justificar e informar a los derechos de tal naturaleza.

El discurso normativo de los Estados constitucionales garantistas y dignatarios tiende a vincular Dignidad y Derechos Fundamentales, aunque a veces con perfiles difusos. Ello puede explicarse debido a que la construcción del concepto "Dignidad" ha sido obra, principalmente, de la filosofía en un afán por destacar el valor intrínseco del ser humano y porque, sólo a partir del constitucionalismo de mediados del siglo XX el Derecho principalmente público - se ha apropiado de tal construcción.

En algunos casos, la relación establecida entre Dignidad y Derechos Humanos se podría caracterizar como de equivalencia ontológica en su status de innatos, en otros, se podría describir como una vinculación de causa efecto, siendo la Dignidad fundamento de los derechos esenciales.

Por ejemplo, resulta interesante - por el alcance de su influencia ${ }^{57}$ - el sistema elaborado por la Declaración Universal de Derechos Humanos en torno al binomio Dignidad -

\footnotetext{
${ }^{54}$ FIX FIERRO, María Cristina, La dignidad de la persona en España y en México, México: Instituto de Investigaciones Jurídicas Universidad Autónoma de México, p.12.

${ }^{55}$ ALDUNATE LIZANA, Eduardo, Derechos Fundamentales, Santiago: Legal Publishing, 2008, p. 97.

${ }^{56}$ En el mismo sentido NOGUEIRA ALCALÁ, Humberto, Lineamientos de interpretación constitucional y del bloque constitucional de derecho, Santiago: Librotecnia, 2006, p 223.

${ }^{57}$ Por ejemplo, la Constitución chilena reproduce casi íntegramente el enunciado del artículo primero de la declaración, también en el primer inciso de su artículo número uno, el cual reza: Las personas nacen libres e iguales en dignidad y derechos. Por su parte, el preámbulo de otros instrumentos regionales de protección de los Derechos Humanos hacen suyos los contenidos de la Declaración Universal de Derechos Humanos. Por ejemplo, la Convención Americana de Derechos Humanos señala: Considerando que estos principios han sido consagrados en la Carta de la Organización de los Estados Americanos, en la Declaración Americana de los Derechos y Deberes del Hombre y en la Declaración Universal de los Derechos Humanos que han
} 
Polit. crim. Vol. 4, N 8 (Diciembre 2009), Art. 3, pp. 383-407 (1-25).

[http://www.politicacriminal.cl/Vol_04/n_08/Vol4N8A3.pdf]

Derechos Humanos. En efecto, tal instrumento en su preámbulo establece que la libertad, la justicia y la paz en el mundo tienen por base el reconocimiento de la dignidad intrínseca $y$ de los derechos iguales e inalienables de todos los miembros de la familia humana, lo cual se ve ratificado por su artículo primero que expresa: Todos los seres humanos nacen libres e iguales en dignidad y derechos. De los mencionados enunciados normativos se desprende que - para dicho instrumento - los valores libertad, justicia y paz son irrealizables sin el reconocimiento de la dignidad y de los derechos esenciales del ser humano y que estos dos últimos conceptos (dignidad y derechos) serían innatos, mas no necesariamente uno se hallaría fundado en el otro.

Distinta es la formulación y rol de la dignidad contenida en la Ley Fundamental de Bonn. Dicha norma expresa en su artículo $1^{\circ}$ :

“1. La dignidad del hombre es inviolable y su respeto y protección constituyen un deber de todas las autoridades del Estado. 2. El pueblo alemán reconoce, en consecuencia, los derechos inviolables e inalienables del hombre como fundamento de toda comunidad humana, de la paz y de la justicia en el mundo."

Hay en este caso un "antes" y un "después" gnoseológicos que tienen una consecuencia ontológica ("reconoce, en consecuencia"; es decir, tienen una consecuencia): a la "dignidad" siguen, como a su fundamento de posibilidad, los "derechos humanos". La dignidad, luego, es más primaria y original que los derechos fundamentales, ${ }^{58}$ sería, en este caso, su fundamento.

sido reafirmados y desarrollados en otros instrumentos internacionales, tanto de ámbito universal como regional, y el Convenio Europeo de Derechos Humanos establece: Considerando la Declaración Universal de Derechos Humanos, proclamada por la Asamblea General de las Naciones Unidas el 10 de diciembre de 1948; Considerando que esta Declaración tiende a asegurar el reconocimiento y la aplicación universales y efectivos de los derechos en ella enunciados. La Declaración Universal de Derechos Humanos dispone también en sus artículos 22 y 23 el derecho de toda persona a obtener la satisfacción de los derechos económicos, sociales y culturales, indispensables a su dignidad y al libre desarrollo de su personalidad, y a recibir una remuneración equitativa y satisfactoria, que le asegure una existencia conforme a la dignidad humana.

Por su parte, la Declaración de la ONU sobre la eliminación de todas las formas de discriminación racial, de 1963, dispone en su artículo primero que: La discriminación entre los seres humanos por motivos de raza, color u origen étnico es un atentado contra la dignidad humana y debe condenarse como una negación de los principios de la Carta de las Naciones Unidas, una violación de los derechos humanos y las libertades fundamentales proclamados en la Declaración Universal de Derechos Humanos, un obstáculo para las relaciones amistosas y pacificas entre las naciones y un hecho susceptible de perturbar la paz y la seguridad entre los pueblos.

Los Pactos Internacionales de 1966 son contestes con el preámbulo de la Declaración de 1948. Además, por ejemplo, el artículo 13 del Pacto Internacional de Derechos Económicos Sociales y Culturales establece: Los Estados Partes en el presente Pacto reconocen el derecho de toda persona a la educación. Convienen en que la educación debe orientarse hacia el pleno desarrollo de la personalidad humana y del sentido de su dignidad, y debe fortalecer el respeto por los derechos humanos y las libertades fundamentales. Lo propio hace el Pacto Internacional de Derechos Civiles y Políticos en su artículo 10.1 al señalar que: Toda persona privada de libertad será tratada humanamente y con el respeto debido a la dignidad inherente al ser humano.

58 COFRÉ LAGOS, Omar, "Los Términos "Dignidad" y "Persona”. Su uso Moral y Jurídico. Enfoque Filosófico", Revista de Derecho de la Universidad Austral de Valdivia, Vol. XVII (Diciembre 2004), pp. 940. 
NUÑEZ LEIVA, José Ignacio. "Un análisis abstracto del Derecho Penal del Enemigo a partir del Constitucionalismo Garantista y Dignatario."

En el mismo sentido se expresa el artículo 10.1 de la Constitución española que reza:

"La dignidad de la persona, los derechos inviolables que le son inherentes, el libre desarrollo de la personalidad, el respeto a la Ley y a los derechos de los demás son fundamento del orden político y de la paz social."

Sin perjuicio de la importancia e impacto del nexo positivo establecido entre dignidad y derechos humanos al interior de cada sistema, resulta de equivalente relevancia precisar el significado o contenido que se atribuye generalmente - en el ámbito jurídico - a la dignidad humana.

Respecto del concepto dignidad, a la hora de reconocer su importancia, tienden a confluir tradiciones profundamente diversas. En efecto, tanto para la filosofía griega (especialmente aristotélica) como para la cristiana y la kantiana, constituye una cualidad moral radical o primaria. Se trata del primer predicado ontológicamente relevante y distintivo de la persona, y la persona es, entonces, el ser cualitativamente primero y distinto del mundo o la creación. Las diferencias entre las distintas tradiciones estriban en el origen de tal predicado. Para la tradición aristotélica la dignidad deriva de la racionalidad humana, para la cristiana de la filiación divina, para la kantiana, ${ }^{59}$ de la calidad moral. ${ }^{60}$

Una de las definiciones más citadas acerca de la dignidad de la persona pertenece a von Wintrich, quien considera que el hombre es un ente ético espiritual que por su naturaleza consciente y libremente puede autodeterminarse, formarse y actuar sobre el mundo que lo rodea. $^{61}$

Desde su significado etimológico, el término "dignidad" es un abstracto del adjetivo "valor" y significa la materialización de un valor, en donde el hombre es el valor supremo. Por tanto, en cuanto el hombre es el valor supremo, el referente axiológico de todo orden constitucional, la dignidad humana, constituirá el fundamento último de la comunidad, y solamente se puede llegar a una posición firme del concepto cuando se acude a la esencia y fundamento de la dignidad de la persona, es decir, se atenta contra la dignidad del hombre cuando se olvida esta esencial superioridad del hombre y se le considera como cualquier otra parte de la naturaleza. ${ }^{62}$ Es entonces, de forma categórica, clara y contundente aquella

\footnotetext{
${ }^{59}$ Es quizá, el alemán Immanuel Kant, el más claro exponente de esta filosofía, quien aborda el estudio de la dignidad del hombre desde una perspectiva moral, sustentándola, precisamente, en la aptitud del hombre de darse a sí mismo leyes universales, sobre la base de esta posibilidad la persona - no como ser natural, sino como ser potencialmente moral - se convierte en un fin absoluto. VÍO VARGAS, Bárbara, Naturaleza, dignidad y derechos humanos, un retorno a los orígenes, Tesis para optar al grado de licenciada en ciencias jurídicas de la Universidad Austral de Chile, p. 21.

${ }^{60}$ QUIÑONES FREDES, María Angélica, El significado de los términos "Persona y Dignidad" en el constitucionalismo contemporáneo. Tesis para optar al grado de licenciada en ciencias jurídicas de la Universidad Austral de Chile.

61 FERNÁNDEZ SEGADO, Francisco, "La dignidad de la persona en el ordenamiento constitucional español”, Revista Vasca de Administración Pública, núm. 43, pp. 52-70., cit. por FIX FIERRO, La dignidad, cit. nota $\mathrm{n}^{\circ} 54, \mathrm{p} .8$.

${ }^{62}$ GONZÁLES PÉREZ, Jesús, La dignidad de la persona, Madrid: Editorial Civitas, 1986, p. 98, cit. por FIX FIERRO, La dignidad, cit. nota $n^{\circ} 54$, p. 9.
} 
Polit. crim. Vol. 4, N 8 (Diciembre 2009), Art. 3, pp. 383-407 (1-25).

[http://www.politicacriminal.cl/Vol_04/n_08/Vol4N8A3.pdf]

cualidad inherente del ser humano que lo hace merecedor de un trato especial por sobre cualquier otra creatura haciéndolo inapto para ser utilizado como medio para cualquier fin, por ser un fin en sí mismo.

En este sentido, para el español Antonio Pérez Luño, la dignidad humana es el valor básico, el principio legitimador de los derechos esenciales; es su fundamento y punto de referencia. Para él, estos derechos supondrían la concreción y explicitación del valor de la dignidad humana $^{63}$ y a su vez, esta última, sería, en opinión de Peces Barba, para aquellos órdenes constitucionales que la reconocen, la base de los valores, principios y derechos fundamentales, ${ }^{64}$ o lo que es lo mismo: la ética pública de la modernidad. ${ }^{65}$

En consideración a lo anterior, y sin perjuicio del debate en torno a la naturaleza jurídica del concepto dignidad (principio o derecho fundamental), ${ }^{66}$ parece claro que ella ante todo, corresponde a un estatus o condición, como la vida o la libertad. El Derecho no confiere vida o libertad sólo las protege, como hace con todo atributo de similar categoría. Pero a diferencia de dichos bienes, que dan cuenta de una realidad extrajurídica - normativamente garantizada - la noción "dignidad" es normativa en si misma. En efecto, su contenido definido por aquella especial atributo del ser humano reclama para él un trato especial por sobre cualquier otra criatura, particularmente el ser considerado siempre como fin en si mismo y nunca como medio. En tal sentido, la específica consagración de ella en un enunciado normativo, inserta como enunciado de principio o derecho fundamental, sólo precisará el alcance de las obligaciones que de ella surgen, más no es la causa de aquellas. Así, en todo ordenamiento jurídico en el cual se consigne a la dignidad como valor constitucional cualquier norma de menor jerarquía que importe el trato del ser humano como medio para un fin, cualquiera sea este, es inválida por contravenir el fundamento esencial de lo que se ha dado en llamar el constitucionalismo humanista o dignatario.

\section{Tensiones entre el Derecho Penal de Enemigo y el Estado Constitucional Garantista (y Dignatario).}

Como ya se adelantó, las objeciones al Derecho Penal de Enemigo son múltiples. Algunos, como Cancio Meliá ${ }^{67}$ o Gracia Martín, ${ }^{68}$ le niegan directamente el status de Derecho Penal. Otros, critican su ineficiencia o lo estiman directamente contrario a los derechos humanos. Nosotros, hemos adelantado que nuestro análisis se dirigirá a probar que, en la actualidad la dinámica de los sistemas jurídicos se orienta por ciertos principios ligados a lo que ha dado en llamarse neoconstitucionalismo y garantismo, los cuales plantean - entre otras cosas -

\footnotetext{
${ }^{63}$ PÉREZ LUÑO, Antonio, Derechos humanos, Estado de Derecho y Constitución, Madrid: Editorial Tecnos, 1984. p. 319.

${ }^{64}$ PECES BARBA, Gregorio, La dignidad de la persona desde la filosofía del derecho, Madrid: Editorial Dykinson, 2003, p. 15.

${ }^{65}$ FIX FIERRO, La dignidad, cit. nota $\mathrm{n}^{\circ} 54, \mathrm{p} .12$.

${ }^{66}$ RUIZ MIGUEL, Carlos, "El significado jurídico del Principio de Dignidad de la Persona", Revista Jurídica del Perú (1996), Trujillo-Perú: Editora Normas Legales, p. 175.

${ }^{67}$ CANCIO MELIÁ, Derecho penal, cit. nota n ${ }^{\circ} 3$, p. 22.

${ }^{68}$ GRACIA MARTÍN, Luis, "Sobre la negación de la condición de persona como paradigma del Derecho Penal de Enemigo”, en: CANCIO MELIÁ/ GÓMEZ-JARA DIEZ, (Eds.), Derecho Penal de Enemigo, cit. nota $n^{\circ} 7$, p. 1065.
} 
NUÑEZ LEIVA, José Ignacio. "Un análisis abstracto del Derecho Penal del Enemigo a partir del Constitucionalismo Garantista y Dignatario."

que el sistema jurídico se estructura de forma estratificada haciendo depender la validez de las normas inferiores de su compatibilidad y conformidad con las superiores. En dichos sistemas, producto de la presencia a nivel constitucional de normas de principios o con fuerte contenido axiológico, elementos propios de la moral crítica se insertan como agentes de racionalización de la producción normativa infraconstitucional.

Uno de los principales criterios de este tipo, cuya presencia es posible constatar en gran parte de las constituciones vigentes, es el principio de la dignidad humana. En este contexto, que nos permitiría incluso hablar de un constitucionalismo garantista y dignatario, propuestas como el Derecho Penal del Enemigo presentan notorias incompatibilidades con el concepto de dignidad humana y por tanto, en virtud de lo ya descrito, serían también inconstitucionales. Para alcanzar tal cometido, resta únicamente que constatemos algunas tensiones y/o incompatibilidades entre el Derecho Penal de Enemigo y la dignidad humana.

Una primera incompatibilidad entre el Derecho Penal del Enemigo y la dignidad humana consiste en que este promueve una segmentación de los miembros de la sociedad. Se trata de una regulación jurídica de las relaciones sociales y de las instituciones sociales que tiende excluir del acceso de ciertos bienes - específicamente del ejercicio de algunos Derechos Fundamentales - a ciertos individuos, todo ello, como una medida para proveer una aparente seguridad al colectivo social. En este caso, la privación de los derechos fundamentales de los enemigos, y por tanto los enemigos en sí, son vistos como medio para un fin.

Una segunda incompatibilidad sustancial estriba en que mediante el Derecho Penal del Enemigo, tal como lo ha dicho Jakobs, el Estado no habla con sus ciudadanos, sino que amenaza a sus enemigos, ${ }^{69}$ en este sentido, nuevamente, los derechos esenciales desconocidos para cierta categoría, se utilizan como medio de comunicación para remitir mensajes de rechazo a sus potenciales enemigos.

En tercer lugar, el Derecho Penal del Enemigo, como negación de la vigencia del derecho penal de ciudadanos - único derecho penal - implica, en virtud de la supresión de todos los límites al ejercicio de la potestad punitiva estatal encarnados en los Derechos Fundamentales, un ejercicio directo de pura coacción, es un dispositivo de fuerza puesto al servicio de la exclusión, y como lo señala Welzel, aquello desconoce la dignidad del hombre, pues lo instrumentaliza y lo convierte en una cosa entre las cosas. ${ }^{70}$

En cuarto lugar, como se ha dicho, el Derecho Penal del Enemigo propone la aplicación de estatutos sancionatorios diversos a quienes estima distintos. Protege a unos y degrada a otros. Empero, la justificación que aporta para derogar un elemento esencial de la esfera normativa de la dignidad humana, esto es que ella pertenece a todos los individuos de la especie humana y requiere para todos ellos idéntico respeto, es manifiestamente insuficiente. En efecto, una de las bases del sistema estipulativo propuesto por el Derecho

\footnotetext{
${ }^{69}$ JAKOBS, Günther, "La ciencia del Derecho Penal ante las exigencias del presente”, Estudios de Derecho Judicial, No 20 (1999), p. 139.

${ }^{70}$ WELZEL, Hans, Introducción a la filosofía del Derecho, Valencia: Editorial Tirant Lo Blach, 2005 , p 251.
} 
Polit. crim. Vol. 4, N 8 (Diciembre 2009), Art. 3, pp. 383-407 (1-25).

[http://www.politicacriminal.cl/Vol_04/n_08/Vol4N8A3.pdf]

Penal de Enemigo consiste en que este se aplicaría a los no personas. Sin embargo, construye la categoría de no persona a partir de la violación del derecho penal de los ciudadanos (personas). Y, como lo anota Gracia Martín, para infringir el derecho penal de ciudadanos, se debe ser ciudadano y persona. ${ }^{71}$ Por lo tanto, el Derecho Penal de Enemigo no tiene destinatarios reales, empíricos, sino que son creados por medio de la aplicación de este derecho penal, no antes. Entonces, el derecho penal de enemigo se termina aplicando a ciudadanos cuya condición se ve degradada por una decisión, normalmente judicial o administrativa - y por tanto no necesariamente representativa de la voluntad popular - de someterlos a tal estatuto. Es una decisión judicial, ni siquiera legal, la que define que seres humanos, y cuáles no, son dignos.

En quinto lugar, el Derecho Penal de Enemigo, positiviza la fuente de la dignidad. Para él, no es la naturaleza humana la que genera aquel atributo invariable, sino que ella depende de una relación sinalagmática entre individuo y Derecho. Sólo si el sujeto se manifiesta como fiel al Derecho vigente adquiere y conserva el status de ciudadano o persona. En tal sentido dichas condiciones serían, nada más que el resultado del cumplimiento de un deber jurídico. $^{72}$

Y en sexto lugar, sin ánimo de presentar la presente lista como únicas incompatibilidades entre Derecho Penal de Enemigo y Dignidad, podemos decir que, como lo afirma Gracia Martín, el destinatario del Derecho - especialmente de sus sanciones - sólo puede ser el individuo, el ser humano, un ente pre jurídico, natural. Es el hombre quien crea al Derecho y no a la inversa. Y tal creación ha de tener en cuenta los atributos propios del ser humano para estructurarse, como su responsabilidad. Esta última, arranca sin lugar a dudas de un sustrato ontológico del ser humano, de lo contrario sería imposible exigirla normativamente: Si el Derecho no se dirige a las fuerzas de la naturaleza ni a los animales, sino al hombre, entonces habrá de ser la estructura óntica del ser humano lo primero que tiene que entrar en consideración. $Y$ es base de aquella esencia, justamente su dignidad. Luego, negar la dignidad, en este contexto, es negar - de paso - una de las bases que estructura al propio sistema jurídico.

\section{Reflexiones finales.}

Habida cuenta de todo lo anterior, podemos extraer las siguientes reflexiones:

- Una de las características actuales del Derecho Penal - y por tanto de la política criminal de la que es tributario - consiste en su tendencia expansionista. Dentro de esta tendencia, y como resultado de la confluencia entre un renovado punitivismo y el Derecho Penal simbólico surgen las bases del denominado Derecho Penal de Enemigo.

- La compleja rúbrica Derecho Penal de Enemigo se construye a partir de una previa distinción estipulativa: la existencia de algunos sujetos que deben ser considerados como ciudadanos y la de otros que han de ser estimados y tratados como enemigos. A

\footnotetext{
${ }^{71}$ GRACIA MARTÍN, El horizonte, cit. nota n ${ }^{\circ} 20$, p. 213.

${ }^{72}$ FEIJOO SÁNCHEZ, Bernardo, "El Derecho Penal del Enemigo", cit. nota n 21, p. 812.
} 
NUÑEZ LEIVA, José Ignacio. "Un análisis abstracto del Derecho Penal del Enemigo a partir del Constitucionalismo Garantista y Dignatario."

partir de ella, propone la configuración y vigencia de secciones del Derecho Penal inspiradas en paradigmas diversos. Una de ellas, el Derecho Penal del Ciudadano, define y sanciona delitos, o infracciones de normas, que llevan a cabo los ciudadanos de un modo incidental y que normalmente son la simple expresión de un abuso por los mismos de las relaciones sociales en que participan desde su status de ciudadanos, es decir, en su condición de sujetos vinculados a y por el Derecho. La otra, el Derecho Penal de Enemigo, configura y castiga actos de aquellos que habrían sido cometidos por individuos que en su actitud, en su vida económica o mediante su incorporación a una organización, se han apartado del Derecho presumiblemente de un modo duradero y no sólo de manera incidental, y por ello, no garantizan la mínima seguridad cognitiva de un comportamiento personal y demostrarían este déficit por medio de su comportamiento.

- El Derecho Penal de Enemigo, se caracterizaría por los siguientes rasgos: un amplio adelantamiento de la punibilidad caracterizado porque la visión retrospectiva del sistema punitivo ha sido reemplazada por una lógica prospectiva, por un aumento de la magnitud de las penas en contraste con el derecho penal "de ciudadanos" desproporcionalidad en las penas - por la disminución e incluso supresión de las garantías procesales individuales (esto último incluso hace hablar a algunos de un Derecho Procesal Penal de Enemigo), y por - siendo esta una característica propuesta por Luis Gracia Martín, el surgimiento de una segmento especial del Derecho Penitenciario destinado a ser aplicado en contra de los destinatarios del Derecho Penal del Enemigo.

- En la actualidad, a nivel de teoría del Derecho y teoría constitucional, dos conceptos o nociones son aceptados como las mejores descripciones del funcionamiento de los sistemas jurídicos: neoconstitucionalismo y garantismo. Según Prieto Sanchís, estos conceptos, sirven para designar un modelo teórico, pero también para referirse a una forma de organización política que se viene abriendo paso desde mediados del siglo $\mathrm{XX}$, que no necesariamente reúne en todas sus manifestaciones signos de uniformidad, pero si unos rasgos esenciales que permiten hablar de algo diferente, no radicalmente nuevo, pero si distinto a lo que pudo representar el Estado de Derecho decimonónico.

- El cambio mencionado se produce a partir de la introducción de conceptos como el valor normativo de la Constitución y la vinculación de la jurisdicción a los Derechos Fundamentales. Ello es el corolario de la fusión de dos tradiciones, la de las constituciones materiales; aquellas que presentan un denso contenido sustantivo integrado por normas de diferente valoración (valores, principios, derechos, directrices) y las constituciones garantizadas, caracterizadas porque su protección o efectividad se encomienda a jueces o, si se prefiere, en su sistema existen normas secundarias, de organización y procedimiento, destinadas a depurar o sancionar toda infracción de las normas sustantivas o relativas a derechos. Así la Constitución se convierte en límite y norma directiva fundamental. Estos tres significados delinean la teoría general del garantismo como proyecto que constituye la otra cara del constitucionalismo, pues este último establece imperativos sustanciales al derecho positivo mediante la positivación constitucional del deber ser. 
Polit. crim. Vol. 4, No 8 (Diciembre 2009), Art. 3, pp. 383-407 (1-25).

[http://www.politicacriminal.cl/Vol_04/n_08/Vol4N8A3.pdf]

- El garantismo no encontrará un espacio de desarrollo tan propicio bajo los paradigmas opuestos al Estado constitucional, y el constitucionalismo precisa del proyecto garantista para condicionar la legitimidad del poder al cumplimiento de las exigencias de los Derechos Fundamentales, pues ambos comparten el reconocimiento de la existencia de un Derecho superior metalegal, que reside en las constituciones, la visión sustancial de la democracia y la idea de evaluar la validez de las normas infraconstitucionales según criterios formales y materiales. Así, desde una perspectiva garantista, la estructura normativa de los Estados constitucionales de Derecho se caracterizan por la pertenencia de las normas vigentes a diversos planos (constitucional, legal, reglamentario, etc.) jerárquicamente ordenados, cada uno de los cuales se configura como normativo respecto del inferior, y como fáctico en relación al superior. Lo cual evidencia el sometimiento absoluto de toda fuente de producción normativa al nivel superior de normas, especialmente a la Constitución. En dicho contexto las prescripciones contenidas en normas superiores condicionan la validez de las normas inferiores, y el cumplimiento de aquellas, define la eficacia de las normas superiores, lo cual rompe, de paso, con la paleopositivista confusión entre validez y vigencia de las normas.

- Probablemente el valor de nivel constitucional que cuya presencia se puede verificar con mayor frecuencia en los ordenamientos jurídicos contemporáneos, es el de la Dignidad Humana, hecho que nos sugeriría la necesidad de completar la rúbrica descriptiva de los sistemas jurídicos actuales el Estado Constitucional Garantista adicionando el calificativo dignatario. Tal como lo sostiene María Cristina Fix Fierro, luego de la segunda guerra mundial se inauguró una nueva época en la cual la convivencia de los pueblos se cimentó en el respeto de la dignidad de todas las personas. En el constitucionalismo de dicha etapa la dignidad humana se eleva a la categoría de núcleo axiológico constitucional y, por tanto, de valor jurídico supremo.

- Respecto del concepto dignidad, a la hora de reconocer su importancia, tienden a confluir tradiciones profundamente diversas. En efecto, tanto para la filosofía griega (especialmente aristotélica) como para la cristiana y la kantiana, constituye una cualidad moral radical o primaria. Se trata del primer predicado ontológicamente relevante y distintivo de la persona, y la persona es, entonces, el ser cualitativamente primero y distinto del mundo o la creación.

- Sin perjuicio del debate en torno a la naturaleza jurídica del concepto dignidad (principio o derecho fundamental), parece claro que ella ante todo, corresponde a un estatus o condición, como la vida o la libertad. El Derecho no confiere vida o libertad sólo las protege, como hace con todo atributo de similar categoría. Pero a diferencia de dichos bienes, que dan cuenta de una realidad extrajurídica - normativamente garantizada - la noción "dignidad” es normativa en sí misma. En efecto, su contenido definido por aquella especial atributo del ser humano reclama para él un trato especial por sobre cualquier otra criatura, particularmente el ser considerado siempre como fin en sí mismo y nunca como medio. En tal sentido, la específica consagración de ella en un enunciado normativo, inserta como enunciado de principio o derecho fundamental, solo precisará el alcance de las obligaciones que de ella surgen, más no es la causa de 
NUÑEZ LEIVA, José Ignacio. "Un análisis abstracto del Derecho Penal del Enemigo a partir del Constitucionalismo Garantista y Dignatario."

aquellas. Así, en todo ordenamiento jurídico en el cual se consigne a la dignidad como valor constitucional cualquier norma de menor jerarquía que importe el trato del ser humano como medio para un fin, cualquiera sea este, es inválida por contravenir el fundamento esencial de lo que se ha dado en llamar el constitucionalismo humanista o dignatario.

- El denominado derecho penal de enemigo - al menos algunas de sus manifestaciones presenta diversas y profundas tensiones con el concepto de Dignidad humana, razón por la cual, al ser aquél un concepto constitucionalizado convierte en inválida cualquier iniciativa de su promulgación como norma vigente en un Estado constitucional garantista (y Dignatario) de Derecho.

\section{BIBLIOGRAFÍA}

ALDUNATE LIZANA, Eduardo, Derechos Fundamentales, Santiago: Legal Publishing, 2008, p. 97.

ALEXY, Robert, El concepto y la validez del Derecho, Barcelona: Editorial Gedisa, 1994, p. 160.

ARAGÓN REYES, Manuel, "La constitución como paradigma", en: CARBONELL, Miguel (Ed.), Teoría del neoconstitucionalismo, ensayos escogidos, Madrid: Editorial Trotta, 2007, p. 35.

BERNAL PULIDO, Carlos, "Refutación y defensa del neoconstitucionalismo", en: CARBONELL, Miguel (Ed.), Teoría del neoconstitucionalismo, ensayos escogidos, Madrid: Editorial Trotta, 2007, p.301.

CALlEGARI, André; DUTRA, Fernanda, "Derecho Penal del Enemigo y Derechos Fundamentales", en: CANCIO MELIÁ, Manuel; GÓMEZ-JARA DIEZ, Carlos (Eds.), Derecho Penal de Enemigo, el discurso penal de la exclusión, Vol. 1, D de F, 2006, p. 329.

CANCIO MELIÁ, Manuel; GÓMEZ-JARA DIEZ, Carlos (Eds.), Derecho Penal de Enemigo, el discurso penal de la exclusión, Vol. 1, D de F, 2006, p. 345.

CANCIO MELIÁ, Manuel, “¿’Derecho Penal” del Enemigo?”, en: JAKOBS, Günther; CANCIO MELIÁ, Manuel, Derecho Penal de Enemigo, Madrid: Editorial Thompson Civitas, 2003, p. 77

, "Derecho penal del enemigo y delitos de terrorismo. Algunas consideraciones sobre la regulación de las infracciones en materia de terrorismo en el código penal español después de la LO/2000", Revista Jueces para la Democracia, $\mathrm{n}^{\circ}$ 44 (2002), p. 19

CASTRESANA FERNÁNDEZ, Carlos, “Guerra al terror y derecho", Revista Jueces para la Democracia, No 43 (2002), p. 6.

COFRÉ LAGOS, Omar, "Los Términos “Dignidad” y "Persona”. Su uso Moral y Jurídico. Enfoque Filosófico", Revista de Derecho de la Universidad Austral de Valdivia, Vol. XVII (Diciembre 2004), pp. 9-40

COMANDUCCI, Paolo, "Forme di (neo)costituzionalismo: una ricognizione metateorica", en: T. MAZZARESE (Ed.), Neocostituzionalismo e tutela (sovra)nazionale dei diritti fondamentali, Torino: Ed. Giappichelli, 2002, pp. 71 y ss. 
Polit. crim. Vol. 4, № 8 (Diciembre 2009), Art. 3, pp. 383-407 (1-25).

[http://www.politicacriminal.cl/Vol_04/n_08/Vol4N8A3.pdf]

,"Formas de (Neo) Constitucionalismo: Un análisis metateórico", Revista Isonomía, No 16 (2002), p. 97.

DEMETRIO CRESPO, Eduardo, "Libertad, seguridad, sociedad del riesgo y Derecho Penal del Enemigo”, en: BERNUZ BENÍTEZ, María José; PÉREZ, Ana Isabel (Coords.), La tensión entre libertad y seguridad, Universidad de la Rioja, 2006, p.113.

, "El "derecho penal del enemigo" darf nicht sein! Sobre la ilegitimidad del llamado "derecho penal del enemigo" y la idea de seguridad", Zeitschrift für Internationale Strafrechtsdogmatik, 9/2006, p. 431

DÍEZ RIPOLLÉS, José Luis, "Derecho Penal Simbólico y los efectos de la pena", Boletín Mexicano de Derecho Comparado, No 103 (2002), p. 63 y ss.

FEIJOO SÁNCHEZ, Bernardo, "El Derecho Penal del Enemigo y el Estado Democrático de Derecho", en: CANCIO MELIÁ, Manuel; GÓMEZ-JARA DIEZ, Carlos (Eds.), Derecho Penal de Enemigo, el discurso penal de la exclusión, Vol. 1, D de F, 2006, p. 802

FERNÁNDEZ SEGADO, Francisco, "La dignidad de la persona en el ordenamiento constitucional español”, Revista Vasca de Administración Pública, núm. 43, pp. 5270 .

FERRAJOLI, Luigi, "El derecho penal del Enemigo y la disolución del Derecho Penal”, en: CARBONELL, Miguel (Ed.), Luigi Ferrajoli: Democracia y Garantismo, Madrid: Editorial Trotta, 2008, p. 236.

, La democracia constitucional, en: CARBONELL, Miguel (Ed.), Luigi Ferrajoli: Democracia y Garantismo, Madrid: Editorial Trotta, 2008, p. 32.

, "Sobre los derechos fundamentales", en: CARBONELL, Miguel

(Ed.), Teoría del neoconstitucionalismo, ensayos escogidos, Madrid: Editorial Trotta, 2007, p. 71.

, Garantismo, una discusión sobre Derecho y democracia, Madrid: Editorial Trotta, 2006, p. 16.

, "El derecho como sistema de garantías" en: Derechos y garantías. La ley del más débil, Madrid: Editorial Trotta, 2004, p. 19.

Trotta, p. 858 .

, Derecho y razón. Teoría del garantísmo penal. Madrid: Editorial

FIX FIERRO, María Cristina, La dignidad de la persona en España y en México, México: Instituto de Investigaciones Jurídicas Universidad Autónoma de México, p. 12.

JAKOBS, Günther, "La ciencia del Derecho Penal ante las exigencias del presente", Estudios de Derecho Judicial, No 20 (1999), p. 139.

GARCÍA FIGUEROA, Alfonso, Principios y positivismo jurídico, El no positivismo principialista en las teorías de Ronald Dworkin y Robert Alexy, Madrid: Centro de Estudios Políticos y Constitucionales, 1998, p 62.

GARZÓN VALDÉS, Ernesto, “Algo más acerca del coto vedado”, Doxa, N o 6 (1989), p. 209.

GONZÁLES PÉREZ, Jesús, La dignidad de la persona, Madrid: Editorial Civitas, 1986, p. 98, cit. por FIX FIERRO, María Cristina, La dignidad de la persona en España y en México, México: Instituto de Investigaciones Jurídicas Universidad Autónoma de México, p. 9

GRACIA MARTÍN, Luis, El horizonte del finalismo y el Derecho Penal del Enemigo, Valencia: Editorial Tirant Lo Blanch, 2005, p 109. 
NUÑEZ LEIVA, José Ignacio. “Un análisis abstracto del Derecho Penal del Enemigo a partir del Constitucionalismo Garantista y Dignatario."

, "Consideraciones críticas sobre el actualmente denominado "derecho penal del enemigo", Revista electrónica de ciencia penal y criminología, $\mathrm{N}^{\mathrm{O}}$ 7 (2005), p. 2.

"Sobre la negación de la condición de persona como paradigma del Derecho Penal de Enemigo", en: CANCIO MELIÁ, Manuel; GÓMEZ-JARA DIEZ, Carlos (Eds.), Derecho Penal de Enemigo, el discurso penal de la exclusión, Vol. 1, D de F, 2006, p. 1065.

GUASTINI, Ricardo, "Sobre el concepto de Constitución", en "Sobre los derechos fundamentales", en: CARBONELL, Miguel (Ed.), Teoría del neoconstitucionalismo, ensayos escogidos, Madrid: Editorial Trotta, 2007, p. 22.

JAKOBS, Günther, "Derecho penal del Ciudadano y Derecho Penal del Enemigo", en: CANCIO MELIÁ, Manuel; GÓMEZ-JARA DIEZ, Carlos (Eds.), Derecho Penal de Enemigo, el discurso penal de la exclusión, Vol. 2, D de F, 2006, p. 37.

, ¿Derecho penal del enemigo? Un estudio acerca de los presupuestos de la juridicidad", en: JAKOBS, Günther, "Derecho penal del Ciudadano y Derecho Penal del Enemigo", en: CANCIO MELIÁ, Manuel; GÓMEZ-JARA DIEZ, Carlos (Eds.), Derecho Penal de Enemigo, el discurso penal de la exclusión, Vol. 2, D de F, 2006, p. 96.

, “Terroristas como personas en Derecho?”, en: CANCIO MELIÁ, Manuel; GÓMEZ-JARA DIEZ, Carlos (Eds.), Derecho Penal de Enemigo, el discurso penal de la exclusión, Vol. 2, D de F, 2006, p. 80.

, "La ciencia del Derecho Penal ante las exigencias del presente", Estudios de Derecho Judicial, No 20 (1999), pp. 119-146.

JULIO ESTRADA, Alexei, "Los tribunales constitucionales y la eficacia entre particulares de los derechos fundamentales", en: CARBONELL, Miguel (Ed.), Teoría del neoconstitucionalismo, ensayos escogidos, Madrid: Editorial Trotta, 2007, p. 148.

MAZZARESE T., "Diritti fondamentali e neocostituzionalismo: un inventario di problemi", pp. 7 y ss.

NOGUEIRA ALCALÁ, Humberto, Lineamientos de interpretación constitucional y del bloque constitucional de derecho, Santiago: Librotecnia, 2006, p. 223.

PECES BARBA, Gregorio, La dignidad de la persona desde la filosofía del derecho, Madrid: Editorial Dykinson, 2003, p. 15.

PÉREZ LUÑO, Antonio, Derechos humanos, Estado de Derecho y Constitución, Madrid: Editorial Tecnos, 1984. p. 319.

PORTILLAS CONTRERAS, Guillermo, "Fundamentos Teóricos del Derecho Penal y Procesal Penal del enemigo", Revista Jueces para la Democracia, no 49 (2004), p. 43.

POZZOLO, S., Neocostituzionalismo e positivismo giuridico, Torino: Ed. Giappichelli, 2001.

"Neoconstitucionalismo y especificidad de la interpretación constitucional", Doxa, No 21 (1998), pp. 339 y ss.

PRIETO SANCHÍS, Luis, "La teoría del Derecho en Principia Iuris", Conferencia pronunciada en la IX Edición de los cursos de post grado en Derecho de la Universidad de Castilla La Mancha, Toledo, España. 2009. Inédito, p. 9

, "El constitucionalismo de los derechos", en: CARBONELL, Miguel (Ed.), Teoría del neoconstitucionalismo, ensayos escogidos, Madrid: Editorial Trotta, 2007, p. 214. 
Polit. crim. Vol. 4, N 8 (Diciembre 2009), Art. 3, pp. 383-407 (1-25).

[http://www.politicacriminal.cl/Vol_04/n_08/Vol4N8A3.pdf]

, Justicia constitucional y derechos fundamentales, Madrid:

Editorial Trotta, 2003, p. 101. Fontamara, 1997. p 17.

Constitucionalismo y positivismo, México: Editorial

QUIÑNONES FREDES, María Angélica, El significado de los términos "Persona y Dignidad" en el constitucionalismo contemporáneo. Tesis para optar al grado de licenciada en ciencias jurídicas de la Universidad Austral de Chile.

RUBIO, F., "La constitución como fuente del Derecho, en La Constitución española y las fuentes del Derecho", Instituto de Estudios Fiscales, Vol. 1 (1979), p. 62.

RUIZ MIGUEL, Carlos, "El significado jurídico del Principio de Dignidad de la Persona", Revista Jurídica del Perú (1996), Trujillo-Perú: Editora Normas Legales, p. 175.

SASTRE ARIZA, Santiago, "Derecho y Garantías", Jueces por la Democracia No 38 (2000), p. 3.

SERRANO, José Luis, Validez y Vigencia, La aportación garantista a la teoría de la norma jurídica, Madrid: Editorial Trotta, 1999, p. 59.

VÍO VARGAS, Bárbara, Naturaleza, dignidad y derechos humanos, un retorno a los orígenes, Tesis para optar al grado de licenciada en ciencias jurídicas de la Universidad Austral de Chile, p. 21

VÍQUEZ, Karolina, "Derecho penal del enemigo ¿Una quimera dogmática o un modelo orientado al futuro?", Polit. crim. No 3 (2007), p. 2.

WELZEL, Hans, Introducción a la filosofía del Derecho, Valencia: Editorial Tirant Lo Blach, 2005, p 251. 